\title{
Social Pragmatic Failure and Its Enlightenments to the Japanese Teaching
}

\author{
Yajie Zhang \\ College of Foreign Languages, Bohai University, Jinzhou, 121013, China \\ 908063810@qq.com
}

Keywords: social pragmatic failure; Japanese teaching; enlightenment; expression form; intercultural communication

\begin{abstract}
Social pragmatic failure is the main cause of the failure of intercultural communication due to the different perceptions of the different cultures in different cultures. The social system of China and Japan is different, the cultural background is different, and hence the pragmatic failure is unavoidable in the process of communication. The purpose of this article is to improve the students' intercultural communication level. First of all, study the characteristics of Japanese communication, including the attention courtesy and understanding of others, ellipsis, collective consciousness, the cautious and modesty of attitude; Then, study the form of social pragmatic failure, including "hailed pragmatic failure, politeness pragmatic failures, taboo pragmatic failures, apology pragmatic failures, greeting pragmatic failures, request pragmatic failure, compliment pragmatic failures and appellation pragmatic failures"; Finally, it puts forward the enlightenment of the Japanese language teaching, mainly is the introduction of Japanese culture and intercultural communication ability training.
\end{abstract}

\section{Introduction}

Pragmatic failures are caused by different cultural differences, and the phenomenon of pragmatic failure is reflected in many aspects. Specifically, the speaker does not see the object, regardless of the communication situation, status and identity, or in violation of social conventions or imperceptibly in communicative norms, the unique cultural values of different time and space against the target language, which leads to the interruption or failure of the communicative action, makes the process of language communication encounter obstacles, and finally leads to the communication can not achieve the desired effect or achieve the perfect communication effect. Only focus on language itself, ignoring the cultural differences between different languages is the main cause of pragmatic failure.

The social pragmatic failure comes from the different perceptions of different cultures. Each culture has its own specific content and connotation, which is hidden behind the moral values, value orientation, way of thinking, social norms and non-standard, which affect the use of language. Social pragmatic failures isn't caused by the violation of grammar rules, but derived from the difference of the way of thinking and habits of different cultures. Because do not know or ignore the social and cultural background in talk each other, caused errors language use and understanding in the process of intercultural communication, resulting in communication can not achieve the desired results. Social pragmatic failures also caused by know less of the cultural background, discourse or inappropriate way of speaking is wrong, has no intention to imposed their own unique culture and consciousness on others through the form of language, regardless of whether these languages comply with others' habit of expression and communication norms.

Intercultural communication refers to communication between native speakers and non-native speakers, also refers to communication of any people who have differences in language and cultural background. The communication of different cultures is a sign of human progress. Ancient Japan has a large number of absorption of Chinese culture. It has be seen clearly the impact of ancient Chinese culture in the Japanese culture and social life, customs and habits so far. Modern China culture is highly influenced by Japanese culture. Especially since the beginning of twentieth 
Century, a large number of Japanese translation of literary works and literary theory have been read, which promote the creation of China new literature prosperity and active literary theory. Modern western bourgeois political economy theory and new knowledge, new ideas, also spread to Japan via Chinese [1]. Foreign cultural exchanges have two channels of official and civil, especially in case the two sides are easy to accept, can often produce special effects. With the deepening of reform and opening up, the field and form of foreign cultural work is constantly changing. After all, China and Japan have different social systems, different cultural backgrounds, different thinking mode and value concepts, pragmatic failure is inevitable in the process of communication. With the development of the world economy and the increasing of international communication, the pragmatic problems in intercultural communication have attracted the attention of scholars both at home and abroad. Social pragmatic failure is the main cause of intercultural communication failure. This paper focuses on the study of social pragmatic failure, which provides a way to improve the teaching level of Japanese and the cross cultural communication ability of college students.

\section{Japanese Communication Characteristics}

Japan is very focusing on interpersonal communication, people pay special attention to the relationship between the eyes and feelings of others, and therefore also pay special attention to their own language expression. Japanese make a sense of a lot of language packaging in communication, use the Japanese expression different with Chinese thinking in many occasions. In many cases, speak Japanese according to the Chinese habit literally, without the vocabulary and grammar mistakes, sometimes will make them feel rude or impolite, and even affect the next communication. This is often the result of not accustomed to the characteristics of the Japanese communication.

Japanese communication has the following characteristics: pay attention to etiquette. Pay attention to their own behavior, always take into account each other's feelings when talking to each other to bring good feeling to others, to weaken order component during the request, make others easy to accept his request; Considerate of others. In order not to make others embarrassed, avoid difficult choose of each other when suggestions or requests are proposed, and used discussed tone, to leave some space to refuse; To omit expression. Don't say or do not write is the biggest characteristic of Japanese communication. Most omits increase vagueness and uncertainty of Japanese, enrich the implication of indirect speech act in Japanese; A strong collective consciousness. The consciousness of unity and cooperation, together in times of trouble among Japanese is very strong. In addition to personal communication, there are many group communication activities in particular. Common communication and entertainment, enrich the spiritual life, full of collective consciousness; The cautious attitude of modesty. Japanese always careful modesty attitude in dealing with others, never be reckless and arrogant. In a courteous and accessible expression, calm thinking and the situation of the mind, to maintain communication to what extent, strictly grasp the sense of propriety. Good, humble attitude, refined and courteous manner, make Japanese more accessible.

\section{Expression Form on Social Pragmatic Failure}

The essence of social pragmatic failure is originated from the cultural conflict, which is related to people's values. Social pragmatic failure is divided into the following 8 categories, as shown in Fig. 1.

(1) Hailed pragmatic failure. Hailed is the most widely used language in communication, in order to maintain normal social relations and promote friendship. In Japan, when you say hello meet others first, is the basis for the construction of interpersonal relationships. Hailed does not put out a boring expression, not look to other places, but focus on making their own words can pass to the other side.

(2) Politeness pragmatic failures. Courtesy, as a lubricant of social life, plays an important role in the smooth running of the whole social life. With the increasing development of international communication, how to get along with people from all over the world, to leave a good impression 
on the people in the world is very important. The Japanese have to say "hello", "please" and "thank you" in any time and at any time.

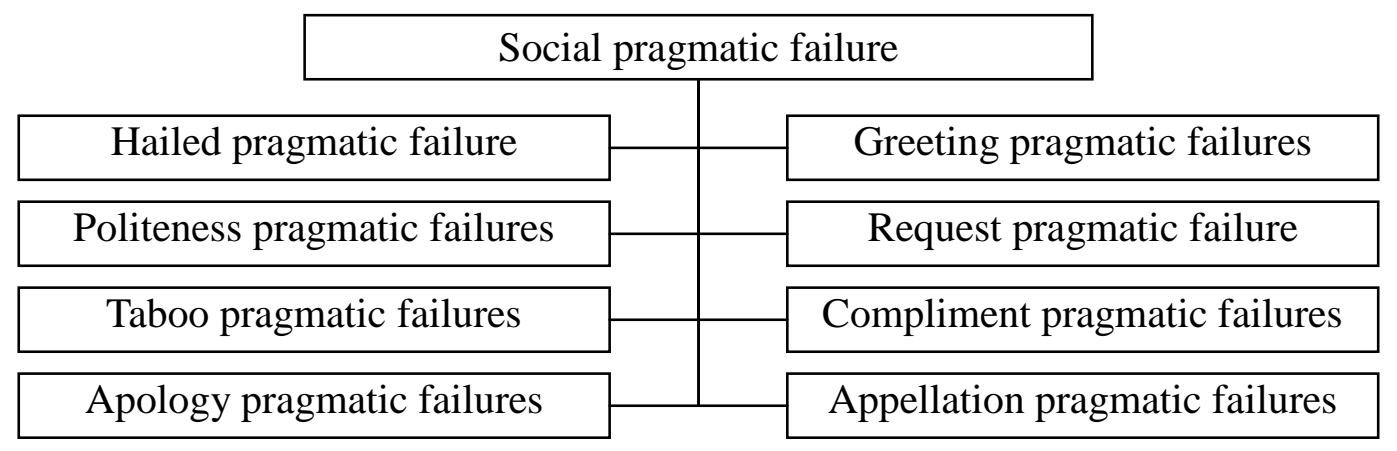

Fig. 1. Expression form on Social pragmatic failure

(3) Taboo pragmatic failures. The taboo is prohibited or taboo terms or words said by some people. The Japanese nation has always been advocating animism, believe that the language has some sort of magic, appeared taboo very early, or from secular habits, or is produced in the religion, all kinds of reasons, covers a very wide, covering living, food and clothing, etc.. To understand taboo euphemism, can reduce the cultural friction with the Japanese exchanges [2].

(4) Apology pragmatic failures. Japan is a country with a strict hierarchy of concepts, the use of language fully reflects the relationship between people, the use of apology is no exception [3]. The Japanese use of the process of apology frequently incommunication, makes the apology terms in Formalization. In the form of Japanese apologies is various and changeful. Although they are all used for expessing apology, but must consider both the speaker and the hearer relations.

(5) Greeting pragmatic failures. Different countries and nations have different cultural backgrounds and historical origins, the greetings and greetings language used are also very different. In Japan, the younger generation to greet the elders is the basic courtesy. In business activities, the first greeted people even is considered to be the dominant party to grasp the right to speak. Greetings if vary from person to person, will break the promise of people, therefore, try to use a fixed greeting.

(6) Request pragmatic failure. Requesting a language is a common kind of communicative action. If the use of their own social norms to exercise or interpret the request speech acts, may lead to pragmatic failure. The causes of the pragmatic failures is just the speaker only grasp the language expression of literal meaning, but ignoring the hearer does not hold the literal meaning beyond the implication because of different culture.

(7) Compliment pragmatic failures. Compliment is a kind of positive speech act, explicitly or implicitly show some "good" things from the speaker to the listener, make positive comments to the listener's advantages and strengths, including possession, quality, intelligence or ability to praise. Through the use of compliments, the speaker can greet and encourage each other, to alleviate the contradiction between the two sides, mutual relationship between them.

(8) Appellation pragmatic failures. Japan is a country very exquisite in language, in addition to the individual calling name without a call, usually with the title in the first name. But these small kana title even directly revealed the closeness of the two persons [4]. Therefore, it is helpful to understand the relationship between the characters of the Japanese environment, and to make clear the respect of all the names.

\section{Enlightenments of Social Pragmatic Failure in Japanese Teaching}

The ultimate goal of the study of pragmatic failure is to improve the level of intercultural communication. Foreign language teaching is one of the ways to cultivate students' intercultural communicative competence. Through the research on the problem of social pragmatic failure, the paper puts forward the following:

(1) Introduction of Japanese culture [5-7]. Culture refers to the spiritual, material and social 
norms which are formed in the process of social history, which is summed up through practice. Language is the most important tool for human communication. It is the main means of communication. People use language to save and transfer the results of human civilization. The integration of language and culture. Language is the key to the production and development of culture, cultural development also makes language more rich; Language is the tool of cultural development, but also developed with the development of culture. Because of the language, human beings create such a glorious and resplendent culture; the creation and development of culture cannot do without language, the change and development of language is inseparable from the cultural environment. A deep understanding of the relationship between language and culture is conducive to foreign language learning, only to understand the target language of the country or region of culture, can really grasp and use of a language. In view of the current Japanese language teaching high school students' language ability and cultural ability of the problem, the introduction of Japanese culture has become an effective way to improve teaching quality. Including the introduction of knowledge culture and communication culture. The purpose of the introduction of knowledge culture is to let the students understand the Japanese way of thinking and values, to enhance the cultural awareness and cultural awareness of college students. In the daily teaching, regard the Japanese cultural background knowledge as the basic content of cultural literacy, for teachers to have objective analysis ability, good knowledge and rational keen observation ability, well versed in Japanese culture, to enhance the students' knowledge of culture; Communication culture can be classified as non language communication culture and the culture of communicative environment, nonverbal communication means in addition to all means of communication language, can be directly used to indicate the attitude, exchange of thoughts and feelings and conceal inner state, so as to enhance the communicative effect. In the specific speech activity, the meaning of language is very rich and very complex, not only has the significance of the language itself, but also has the special significance to the language environment, not only on the understanding from the meaning of language itself, must contact and depend on the language environment, to eliminate ambiguity and ambiguity in verbal communication.

(2) Intercultural communicative competence training [8-10]. Intercultural communication refers to people with different cultural background in the process of communication. Various language skills are necessary means of communication, language and cultural knowledge, social background knowledge is an indispensable factor in communication. Because of the differences between languages and cultures, people in different countries and regions will inevitably lead to errors in the process of intercultural communication, which will lead to intercultural pragmatic failure and the effect of communication. Although the Japanese language system comes from Chinese, there is a huge difference between the two countries in both language and culture. Therefore, even if the students have a solid knowledge of the language, and lack of understanding of Japanese culture, the Japanese habits and the values of the Japanese, there is also inevitable exchange barriers or misunderstanding in Japanese exchange. The primary task of Japanese teaching is to cultivate students' ability to use language. On this basis, it should pay attention to the cultivation of students' intercultural communicative competence. The communicative competence includes not only the understanding and mastery of the language form, but also the knowledge system of the use of language in the form of communication. In the process of teaching, more organization of dialogue practice, set different situations, make the students do self expression. It also can use the textbook content to exercise the student's communicative ability, make the students play the role of practice dialogue, to further understand the Japanese language and culture. In real life, you can contact the Japanese friends, not only to learn the true cultural customs of Japan, but also to enhance communication skills. Language communication is very important, but non verbal communication can not be ignored. In intercultural communication, if you can not properly use non-verbal communication, it is easy to produce unnecessary misunderstanding, affect the communication effect, even lead to the failure of communication seriously. While cultivating students' intercultural communicative competence, teachers should pay attention to the cultivation of non cultural 
communication and avoid misunderstanding and conflicts in intercultural communication, which can ensure the smooth progress of intercultural communication.

\section{Conclusion}

From the perspective of pragmatics, the accumulation of language knowledge is indispensable, but it is not the ultimate goal of learning language. The process of language teaching is "pragmatic competence". Students "pragmatic competence" strong or weak, which marks the actual level of language learning, students "pragmatic competence" high or low, measures the actual performance of language teaching. To pay attention to the cultivation of students' consciousness and ability of intercultural communication in the teaching process, in-depth understanding of Japanese culture, to enhance the sensitivity and insight of Japanese language and culture, solve social pragmatic failure problem fundamentally.

\section{References}

[1] Q. Q. Sun, "Reflections on Sino Japanese cultural exchanges," Guangming Daily, 2012-9-1.

[2] Y. N. Dong, M. L. Cao, "The use of Japanese social communication taboo," Chinese and foreign entrepreneurs, vol. 33, no. 17, pp. 259-260, 2016.

[3] X. P. Liu, " A discussion on the guiding role of the differences between Japanese and Japanese in the teaching of Japanese," China Education Innovation Herald, vol. 38, no. 35, pp. 77, 2009.

[4] Through Japan Information, "Comparison of various forms of address in Japanese," http://study.kantsuu.com/201504/20150409134133_354699.shtml, 2016-9-9.

[5] J. Peng, " A discussion on the guiding role of the differences between Japanese and Japanese in the teaching of Japanese," China Education Innovation Herald, vol. 38, no. 35, pp. 77, 2009.

[6] Y. Zhou, L. Yu, "On the influence of language environment on the meaning of language," Journal of Huanggang Polytechnic, vol. 9, no. 4, pp. 78-80, 2007.

[7] J. Y. Wang, J. H. Liang, "Research on the problem of culture introduction in Japanese Teaching," Foreign Language and Literature Research, vol. 17, no. 8, pp. 114-116, 2015.

[8] NAREN Tuya, "On the Development of Japanese Learners' Inter-cultural Communication Competence in Higher Education," Foreign Language and Literature Research, vol. 2, no. 2, pp. 93-97, 2016.

[9] L. Chen, "Intercultural communication and college Japanese teaching," Western China Quality Education, vol. 2, no. 1, pp. 145-146, 2016.

[10] H. Zhang, W. D. Chen, "Cultivation of Intercultural Communicative Competence in Japanese Teaching," Journal of Xiangyang Vocational and Technical College, vol. 14, no. 1, pp. 105-107, 2015. 